\title{
In-vitro study on the Removable Partial Denture Framework Adaptation in CAD/CAM and Conventional Techniques.
}

\author{
Hanan Ali Mohamed, BDS, * Hani Ibrahim Eid, ** Shimaa Lotfy, \\ DDS, MS, PhD
}

\section{Abstract}

Introduction: Removable partial dentures (RPDs) represent asigni-cant proportion of prostheses used in patients over 65 years of age in developed countries, the importance of an accurately fitting removable prosthesis is essential for its success. The present study was done to evaluate the adaptation of removable partial denture manufactured by conventional versus CAD /CAM techniques.

Methods: Identical stone models (Kennedy class III modification one) were used in this study. Rest seat preparations and beading were done. Duplication of the prepared models was done. Duplicated models were scanned by 3Shape desktop scanner .Models were virtually surveyed and needed modifications were done .Finally Cast will be surveyed and needed modifications will be done. The proper design of Kennedy maxillary class III modification one RPD will be done virtually using 3 shape software. Two saddles connected with middle palatal strap will be selected according to their structural specifications. The models will be divided into two groups.

Group A: The wax pattern of partial denture design was milled.

Group B: The wax pattern of partial denture design conventionally applied to the refractory casts.

All wax patterns of both groups converted to metal framework through conventional lost wax technique. Then the adaptation of removable partial denture was evaluated through surface matching software.

Results: The results obtained from this study showed that removable partial denture framework obtained from milled wax pattern had higher adaptation than

\footnotetext{
* Profeesor of Prosthodntics, ain Shams University

** Assistant Professor of Prosthodontics, Ain shams university
} 
the framework obtained from manually applied wax pattern but the difference wasn't statistically significant

Conclusions: Under the circumstances of this study, it can be concluded that digital technology can lead to more acuuuerate results more than conventional technique.

\section{Materials and Methods}

This in-vitro study was applied on an educational maxillary stone model (Kennedy class III modification.1), where the abutments were the first premolar and second molar bilaterally. Rest seat preparations were made in the near zone of the edentouls area in the first premolar and second molar bilaterally. The preparation is done by size two round bur, the rest seat was prepared following the anatomy of the triangular fossa with its apex toward central fossa and the base toward marginal ridge, The width of it was one third the mesio-distal width and the depth was $1.5 \mathrm{~mm}$. Midline was drown from incisive papilla which represent midline anterior to point measured midway in the palate. Beading was done at the borders of maxillary major connector by scrapping a groove $0.5 \mathrm{~mm}$ in depth and width. The final prepared model was duplicated using silicone material to form silicone mold to pour four identical stone models which divided into two groups: Four identical stone models were divided into two groups:

Group A: The wax pattern of partial denture design was milled.

Group B: The wax pattern of partial denture design conventionally applied to the refractory casts.

All wax patterns of both groups converted to metal framework through conventional lost wax technique.

The 3shape D850 desktop scanner * was used $^{* *}$ to scan the final prepared stone model. The 3D scanner composed of blue led 2X 5 MP cameras with motion supporting several axes system.

\footnotetext{
* 3Shape,Denmark
}

** 3Sahpe Dental System, Denmark
Prepared stone model was fixed inside the scanner on the plate with its labial surface facing the inside of the scanner, and then scanning order was given. New order software system was selected and removable partial denture framework design was chosen. III-Designing of the models

\section{Designing of the models were done using 3Shape software in the following steps:}

\section{A-Surveying the prepared model}

Electronic surveying was done; the digital surveying will determine all favorable and unfavorable undercuts. The proper path of insertion was chosen after tilt modification to ensure the presence of $0.5 \mathrm{~mm}$ undercuts in the retentive undercuts for the retentive tip of the retentive clasp arm. The location and the depth of the favorable undercuts were selected according to the determined path of insertion and appeared in form of colored scale.

\section{B-Block out the prepared model}

The software blocked all unfavorable undercuts and show only favorable undercuts where the retentive tip of the retentive clasp arm were seated.

\section{C-Drawing the removable partial denture components}

\section{1-Denture base design}

Denture base was chosen, the denture base outline extended $2 \mathrm{~mm}$ from the ridge crest buccally and palatally following the ridge contour and $1 \mathrm{~mm}$ away from the abutments mesodistally. By software tools dots were placed on the periphery of the ridge and then connected together to create the denture base. Notches in the middle of the denture base were done which used as reference points where the adaptation was measured.

\section{2- Major connector design}

Middle palatal strap was chosen as a major connector. The width of the middle palatal strap was $8 \mathrm{~mm}$ in width. Notches were made corresponding to the midline on the anterior 
and posterior border of the major connector which used as reference point where the adaptation measures were taken

\section{$\underline{\text { 3-Clasp assembly design }}$}

Rest seat was adapted on each abutment .Aker clasp was chosen for each abutment except the left side premolar. The retentive arm was drawn on the buccal surface of each three abutments and tapered from occlusal direction to engage $0.1 \mathrm{~mm}$ undercut below the survey line. The retentive and reciprocal arms were joined to the occlusal rest to ensure unity of the framework.

\section{Iv-Finalizing the design}

The junction between the denture base and the major connector (external finish line) was drawn; Smoothening of all frameworks was done. After all components chosen with desirable shape and location, the final design was established, the STL (Standard Tessellation Language) file of the removable partial denture design was produced by the software which used for construction of removable partial denture framework._Iv-Casting of the partial denture design_

\section{For group A:}

The design in STL was milled in wax and then the milled wax pattern was pressed into cobalt chromium by the lost wax technique.

Twenty mm blank of castable machinable wax was milled after installing the STL file on the 5 axis milling* to produce the final wax pattern for the removable partial denture frame work. The pattern was removed from the milling machine and sprued, then the milled wax pattern was pressed into cobalt chromium by conventional lost wax technique. The wax pattern was removed from the milled blank by special cutter to avoid wax distortion and then returned to the refractory cast so that each component was seated in its planned position. The pattern was sprued by different gauge sprues. The assembly was invested with special phosphate bonded investment material. The ring preheated in the oven (between $630^{\circ} \mathrm{C}$ and $850^{\circ} \mathrm{C}$ ) for the wax elimination .The melting procedure for the cobalt chromium was done at $500{ }^{\circ} \mathrm{C}$ for the completed pressing process. The partial denture framework was disinvested manually; removal of sprues and cleaning of framework was done by air abrasion. Polishing of the framework was done then the final partial denture framework was reseated on the master cast. These steps involved to all frameworks of this group.

\section{For group B}

The wax pattern applied to the refectory cast. Denture base was applied first from readymade wax then the retainer. Like group A The pattern was sprued by different gauge sprues The two main large diameter sprues were connected to the major connector bilaterally, and finally the major sprues were connected to mould plate as preparatory step for investment preparatory step for investment material .The ring preheated in the oven (between $630^{\circ} \mathrm{C}$ and $850^{\circ} \mathrm{C}$ ) for the wax elimination the melting procedure for the cobalt chromium was done at $500^{\circ} \mathrm{C}$ ) or the completed pressing process.

The partial denture framework was disinvested manually, finally polishing of the framework was done by then the final partial denture framework was reseated on the cast. These steps involved to all frameworks of this group.

\section{VI -Evaluation of adaptation of the framework}

Computer graphic coordinate measures system $^{* *}$ was used to measure adaptation of partial denture framework.

Partial denture frameworks of each group were scanned by 3 Shape desktop scanner then STL file of each framework was obtained. Superimposition between the reference and measured date were done .Measurement of adaptation was done at denture base bilaterally and major connector at predetermined areas (notches) at three axes $\mathrm{X}, \mathrm{Y}$ and $\mathrm{Z}$ for each

\footnotetext{
* K5 -Five axes dry milling VHF,Germany
} 
point. Difference in fit was recorded and tabulated for statistical analysis.

\section{RESULTS}

The results of this study are shown in table (I-III) and figures (49-51).Data is presented as Mean and Standard deviation (SD) values for both groups. Group A (design was milled in castable wax, and then the milled wax was pressed into cobalt chromium by lost wax technique).and group B (wax pattern applied conventionally and then pressed into cobalt chromium by lost wax technique).

All data of the current study were collected and statistically analysis was performed with IBM ${ }^{1}$ SPSS statistics version 2o for windows.Student t test was used to compare between the groups. Apropabibllity level of.005 was considered statistically significant.

\section{Comparison between the two studied groups regarding the adaptation of partial denture framework:}

A-Comparison between the two studied groups regarding the adaptation of partial denture framework at major connector was shown in table (I) and figure 49.

Table (I): Mean Standard deviation and P value of student T test for the adaptation in two groups at major connector.

\begin{tabular}{|c|c|c|c|c|}
\hline \multirow{3}{*}{ Major connector } & \multicolumn{2}{|c|}{ Mean } & SD & P Value \\
\cline { 2 - 5 } & $\begin{array}{c}\text { Group A } \\
\text { (Milled) }\end{array}$ & 60 & 17.299 & .21 (ns) \\
\cline { 2 - 5 } & Group B & 74 & 20.77 & .32 (ns) \\
\hline
\end{tabular}

Figure 49: Bar chart representing mean and standard deviation values for adaptation at major connector in the two groups

Table I and figure 49 show higher adaptation in group A (milled) than group B (conventional) at major connector

Table (II): Mean, Standard deviation, and P value of student $T$ test for the adaptation in two groups at right denture base.

\begin{tabular}{|c|c|c|c|c|}
\hline & \multicolumn{2}{|c|}{ Mean } & SD & P Value \\
\hline \multirow{2}{*}{$\begin{array}{c}\text { Right denture } \\
\text { base }\end{array}$} & $\begin{array}{c}\text { Group A } \\
\text { (Milled) }\end{array}$ & 109.7 & 18.271 & $.32(\mathrm{~ns})$ \\
\cline { 2 - 5 } & $\begin{array}{c}\text { Group B } \\
\text { (Conventional) }\end{array}$ & 142.4 & 26.02 & .32 (ns) \\
\hline
\end{tabular}

Figure 50: Bar chart representing mean and standard deviation values for adaptation at right denture base in the two groups

Table (II) and figure 50 shows higher adaptation of removable partial denture framework in group A (milled) than group B (conventional) at right denture base.

Table (III): Mean, Standard deviation, and P value of student T test for the adaptation in two groups at left denture base.

\begin{tabular}{|c|c|c|c|c|}
\hline & \multicolumn{2}{|c|}{ Mean } & SD & P Value \\
\hline \multirow{2}{*}{ Left denture base } & $\begin{array}{c}\text { Group A } \\
\text { (Milled) }\end{array}$ & 127.5 & 21.67 &, 31 (ns) \\
\cline { 2 - 5 } & $\begin{array}{c}\text { Group B } \\
\text { (Conventional) }\end{array}$ & 180.1 & 27.75 &, 31 (ns) \\
\hline
\end{tabular}


Figure 51: Bar chart representing mean and standard deviation values for adaptation at left denture base in the two groups Discussion

Over the years there have been significant advancements in the field of prosthodontics .Current CAD-CAM technology being still expensive in the dental market in the coming years the current CAD-CAM systems are expected to completely eliminate or markedly decrease the conventional laboratory steps in partial and complete denture construction.

The method described in this study offers potential advantages. Now it may be possible to virtually build a framework on a scanned cast using a "drag and drop' 'icon on the software .This would reduce inter operator variability, and increase speed and economy over traditional handcrafting and investment casting techniques. However, there is need for refinement and development of the software and equipment for dental requirements and for further studies in this area.

The data of this study revealed that there was no significant difference in the adaptation of removable partial denture framework in both groups., now CAD-CAM technology plays an important role in removable partial denture construction regarding the design and construction of the partial denture. This was confirmed by Khamisy NE et al (121) who mentioned that conventionally fabricated RPDs recorded significant higher gaps (lesser adaptation) between RPD components and supporting tissue in $\mathrm{mm}$ and lower percentage of contact than removable partial denture designed and fabricated by cad cam at different sites of measurements. The conventional process includes more difficult steps with higher number of potential sequence such as manual construction of the wax pattern. Which play important role in the final results.

The adaptation of removable partial denture obtained from milled wax patterns is influenced by software program. This confirmed by Stock it all (122) who mentioned that the accuracy of fit of milled removable partial denture was better than the conventional one. The conventional process includes more difficult sequence with higher number of potential source of errors which provide small path differences of milling machine. Small path differences offer a smooth inner surface and thus increase the adaptation of the final prosthesis in relation to the soft tissues ${ }^{(123) .}$

The results obtained from this study showed that removable partial denture framework obtained from milled wax pattern had higher adaptation than the framework obtained from manually applied wax pattern but the difference wasn't statistically significant. The frameworks in group (A) were pressed in mold made from milled castable wax rather than manually constructed wax pattern which cause increase adaptation due to elimination of multiple steps and human errors associated with manual construction of wax pattern.

Abduo et al, Rekow et al (123) reported that the accuracy of CAD/CAM system milling is shown to be within $10 \mu \mathrm{m}$. CAD software allows continuous control of individual elements of the prosthesis, and hence the control of the implementation of planned mechanical parameters, and at the same time designing of minimally visible attaching elements. Then, using the CAM, it is possible to precisely produce the whole prosthesis with an accuracy of up to $0.1 \mathrm{~mm}$. Therefore, it is reasonable to have a more accurate fit with the CAD/CAM RPDs because there was no duplication of the master cast, and the virtual design was carried out directly to the desired position on the scanned master cast and metallic RPDs milled directly from the metallic disc without any laboratory procedure. 


\section{Conclusion}

Under the circumstances of this study, it can be concluded that digital technology can lead to more acuuuerate results more than conventional technique .

\section{References}

Gupta, Naeveen, Bahsin, Abhlilasha, Parul, Malhotra, Pankaj:Combined Prosthesis with ExtracoronalCastable Precision Attachments (Case Reports) January 2013.

Mccracken:Removable partial prosthodontics $12^{\text {th }}$ edition. St Louis, Mosby, 2005.

Stewart: Clinical Removable Partial Prosthodontics: Ed3,2003.

Curtis DA(1), Curtis TA, Wagnlid GW, Finzen FC: Incidence of various classes of

removable partial dentures.;67(5):664-7. May 1992.

Manderson R.D., Wills D.J., Picton D.C.A.: Biomechanics of denture supporting tissue, Mosby, 1979:98.

WatahaJC,MesserRL:Castingalloys. Dental Clinics of North America. ;48(2):499-512, 2004

Potter R.B., Appleby R.C, Adam C.D.: Removable partial denture design, A review and a Challenge ;17(1):63-68, 1967.
Jaafar A., Karl L., Mohammed B.: Trends in Computer- Aided Manufacturing in Prosthodontics. A literature review. International Journal of Denistry.2014 Apr.

Miyazaki T, Hotta Y.: CAD/CAM systems available for the fabrication of crown and bridge restorations. Australian Dental Journal.;56(1):97-106, 2011.

Beuer F, Schweiger J, Edelhoff D. Digital dentistry: An overview of recent developments for CAD/CAM generated restorations. British Dental Journal.;204(9):505-511, 2008

Abduo J, Lyons K.: Rationale for the use of CAD/CAM technology in implant prosthodontics. International Journal of Dentistry,2013.

Osborne J., Lammie G.A. \&Larid W.R.E: Osborne \&Lammie's partial dentures $5^{\text {th }}$ ed. Oxoford: Blackwell Scientific.295-318. 1986 